Review began 11/03/2021 Review ended 11/11/2021 Published 11/15/2021

\section{() Copyright 2021}

Paul et al. This is an open access article distributed under the terms of the Creative Commons Attribution License CC-BY 4.0. which permits unrestricted use, distribution, and reproduction in any medium, provided the original author and source are credited.

\title{
Comparison of Fluorometric and UV Spectrophotometric Findings for DNA Isolated From Formalin-Fixed Paraffin-Embedded Blocks, Fine Needle Aspiration Cytology Smears, and Blood
}

\author{
Pranoy Paul ${ }^{1}$, Swati Rajput ${ }^{1}$, Prashant Joshi ${ }^{2}$, Manisha Naithani ${ }^{1}$, Nilotpal Chowdhury ${ }^{2}$, Shalinee Rao ${ }^{1}$, \\ Manju O. Pai ${ }^{1}$ \\ 1. Division of Molecular Biology, Proteomics and Metabolomics, All India Institute of Medical Sciences, Rishikesh, IND \\ 2. Department of Pathology and Laboratory Medicine, All India Institute of Medical Sciences, Rishikesh, IND
}

Corresponding author: Manju O. Pai, manjuohripai@gmail.com

\begin{abstract}
Introduction: Fine needle aspiration cytology (FNAC) smear may serve as a convenient sample for DNA extraction for molecular pathology in addition to more commonly used formalin-fixed paraffin-embedded (FFPE) sections. DNA quantification done by fluorometer is more accurate than UV vis spectrophotometer regardless of the source. This study was conducted to compare DNA yield and quality from cytology smears, FFPE sections and peripheral blood using both fluorometer and spectrophotometer. Further, introspection was made to check for the adequacy of DNA extracted from cytology smears with respect to DNA extracted from core biopsies.
\end{abstract}

Method: DNA was extracted from 10 fresh peripheral blood samples, core biopsies and FNAC smears. The DNA was quantified using a fluorimeter and UV vis spectrophotometer in all cases.

Results: Statistically significant difference was seen between the data obtained from UV vis spectrophotometry and flourometry. The quantity of DNA extracted from FNAC smears was higher than that of core biopsy as per fluorometry data (mean DNA of core biopsy $=1.9 \mathrm{ng} / \mathrm{\mu l}$, of FNAC $=3.3 \mathrm{ng} / \mathrm{\mu l}$ ).

Conclusion: DNA estimation by fluorometry is more accurate and precise than spectrophotometry in FFPE, FNAC and whole blood samples. DNA yield from FNAC slides is comparable to that from core biopsies.

Categories: Pathology, Quality Improvement

Keywords: fluorometer, uv spectrophotometer, ffpe, blood, fnac, dna

\section{Introduction}

Formalin-fixed paraffin-embedded (FFPE) tissue has been the cornerstone of histopathological examination. As per the evidence in literature, Goelz et al. first described a method to isolate double-stranded DNA from archived FFPE blocks in 1985 [1]. Archival cytology smears obtained from fine needle aspiration cytology technique (FNAC) can be another appropriate source for isolating nucleic acids for downstream processes [24]. The quality of DNA extracted from these samples is significantly compromised due to fragmentation and chemical modifications in the extracted DNA [5,6]. In contrast, DNA extracted from fresh blood has relatively higher DNA yield and shows less fragmentation with increased amount of longer DNA fragments [7].

The most commonly used method for nucleic acid estimation in reference labs is UV vis spectrophotometer which relies on the absorbance of light by nucleic acids at different wavelengths [8]. A simplified and portable but less commonly used method of estimating nucleic acid concentration is by fluorometer. According to numerous independent studies, fluorometer is shown to be a much more accurate and reproducible mode of nucleic acid estimation $[9,10]$. UV vis spectrometer is known to over-estimate DNA or RNA quantity by manifolds $[5,10]$. Since most mutation analysis kits available in the market do not explicitly mention mode of DNA estimation in their methodology for preparation of amplification mix, using UV vis spectrophotometer readings to set up a reaction may severely decrease the sensitivity of the assay.

To this effect we compared DNA yield and their quality from cytology smears, FFPE sections and peripheral blood using both fluorometer and spectrophotometer. Another objective of the study was to assess the adequacy of scrapings from archived FNAC slides vis a vis FFPE blocks with respect to DNA yield.

\section{Materials And Methods}


This study was conducted in the Division of Molecular Diagnostics in collaboration with the Department of Pathology, All India Institute of Medical Sciences, Rishikesh. Mutation analysis for EGFR and KRAS is routinely done in the laboratory using FFPE blocks. In cases where biopsy is unavailable, cytology samples in the form of cell blocks and smears are utilized to extract DNA. We routinely receive peripheral blood samples for detection of HLAB-27 mutations. For this research study, we chose 10 routine samples each from FFPE blocks, cytology smears and peripheral blood whose DNA was isolated in the period between April 2020 to April 2021 for routine testing.

\section{DNA extraction from FFPE blocks}

FFPE blocks were prepared from tru-cut biopsies of lung carcinomas. Histopathology slides were screened and tumour area was marked. Blocks having more than $20 \%$ tumour area were selected and three to four shavings of 10-micron thickness were taken for DNA extraction. Extraction was done using QIAamp DNA FFPE tissue kit (Qiagen, Hilden, Germany). DNA was eluted in 40ul elution buffer supplied by the manufacturer.

\section{DNA extraction from stained cytology smears}

After establishing the diagnosis of non-small cell lung carcinoma on smears, slides having the highest cellularity were selected. In cases where cellularity was low ( $<500$ cells) multiple stained smears were taken and minimum cellularity was established at $\sim 500$ cells per case. Alcohol-fixed Papanicolaou (PAP) stained smears were preferred over air-dried smears stained with May Grunwald Giemsa (MGG) stain, however in three cases MGG stained slides were chosen due to higher cellular count. The slides were dipped in xylene bath for a minimum of 48 hours at $56^{\circ} \mathrm{Celsius}$ or till their cover slips slipped off. The slides were decolourised by dipping into $0.5 \%$ acid-alcohol solution for 30 seconds. Slide scrapings were taken from each of the slides in a microcentrifuge tube. DNA extraction was done using QIAamp FFPE DNA extraction kit (Qiagen) using the manufacturer's protocol with minor modifications. The modifications made were as follows: addition of xylene for deparaffinisation in the microcentrifuge tube was avoided, and incubation was only done for two to four hours at $56^{\circ} \mathrm{Celsius}$ with proteinase K. DNA was eluted in $40 \mu \mathrm{l}$ elution buffer supplied by the manufacturer.

\section{DNA extraction from whole blood}

DNA was extracted from the peripheral blood using DNeasy Blood and Tissue kit (Qiagen) using 200 $\mu$ l whole blood as per the manufacturer's instruction. DNA was eluted in 100pl elution buffer.

\section{DNA estimation}

DNA quantity was estimated using Quantus Fluorometer kit (Promega, Madison, WI, United States) for further downstream reactions. Eluted DNA was also measured using QIAxpert UV/VIS spectrophotometer (Qiagen). DNA quality was estimated using 260/280 ratios.

\section{DNA gel electrophoresis}

Gel electrophoresis was done for all the extracted samples on $1.5 \%$ agarose gel at $150 \mathrm{~V}$ for 30 minutes using $8 \mu \mathrm{l}$ DNA samples mixed with $2 \mu \mathrm{l}$ bromophenol blue dye. For reference a 100 base pair DNA ladder was used. The gel was visualized under UV light using Azure Biosystems c300 Gel documentation system (Azure Biosystems, Dublin, CA, USA).

\section{Results}

Mean DNA yield in blood, FFPE and FNA cytological smear measured by fluorometer and spectrophotometer

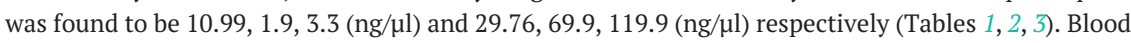
samples showed relatively lesser variation compared to FFPE and FNAC samples. Average total yield of DNA in blood, FFPE and FNA cytological smear measured by fluorometer and spectrophotometer was found to be 1099, 76.52, 132.3 (ng) and 2976, 2797, 4758.7 (ng) respectively. A representative gel electrophoresis picture (1.5\% agarose) showed relatively intact DNA in blood samples, whereas both FNAC and FFPE samples showed smeared patterns suggestive of fragmented DNA (Figure 1). 


\section{Cureus}

\begin{tabular}{|c|c|c|c|c|c|c|c|}
\hline Case & $\operatorname{TLC}\left(\times 10^{3} / \mu \mathrm{ll}\right)$ & DNA (F) (ng/pl) & DNA (S) (ng/pl) & $260 / 280$ & Difference (S- F) & Total yield (F) (ng) & Total yield (S) (ng) \\
\hline Blood 1 & 9.4 & 23 & 43.5 & 2.2 & 20.5 & 2300 & 4350 \\
\hline Blood 2 & 4.2 & 6.3 & 24.9 & 2.16 & 18.6 & 630 & 2490 \\
\hline Blood 3 & 5.1 & 7.7 & 22.4 & 2.57 & 14.7 & 770 & 2240 \\
\hline Blood 4 & 7.4 & 11 & 38.3 & 2.14 & 27.3 & 1100 & 3830 \\
\hline Blood 5 & 4.9 & 10 & 32.4 & 1.99 & 22.4 & 1000 & 3240 \\
\hline Blood 6 & 4.9 & 7.5 & 35.21 & 1.98 & 27.71 & 750 & 3521 \\
\hline Blood 7 & 5.6 & 15 & 20.7 & 1.88 & 5.7 & 1500 & 2070 \\
\hline Blood 8 & 4.1 & 4.6 & 23.2 & 1.8 & 18.6 & 460 & 2320 \\
\hline Blood 9 & 5.2 & 6.8 & 21.25 & 2.1 & 14.45 & 680 & 2125 \\
\hline Blood 10 & 8.6 & 18 & 35.8 & 1.85 & 17.8 & 1800 & 3580 \\
\hline
\end{tabular}

TABLE 1: DNA values from haematology smears

TLC- Total Leukocyte Count, S- Spectrophotometer, F- Fluorometer

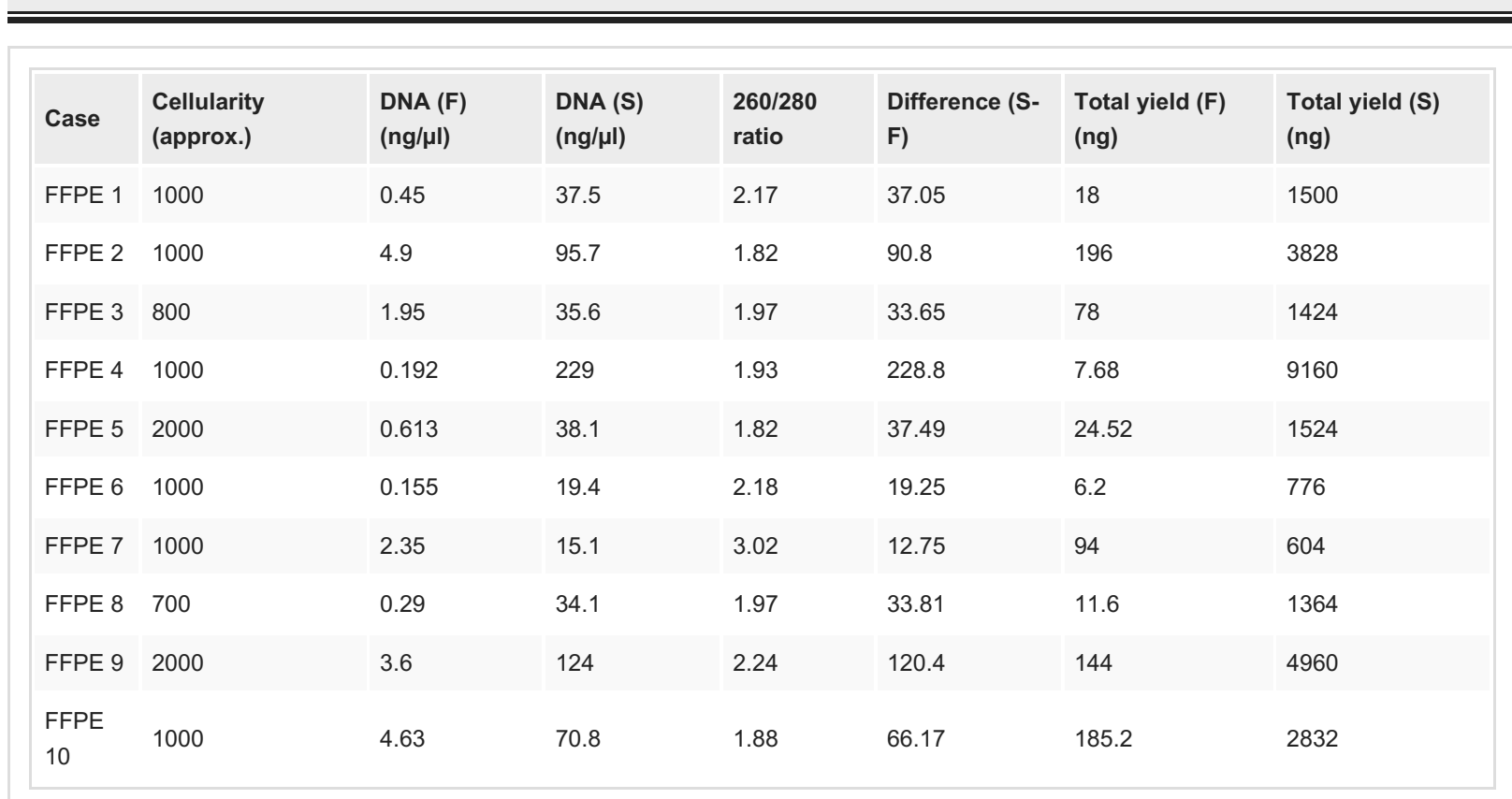

\section{TABLE 2: DNA values from FFPE blocks}

S- Spectrophotometer, F- Fluorometer, FFPE- formalin-fixed paraffin-embedded 


\section{Cureus}

\begin{tabular}{|c|c|c|c|c|c|c|c|}
\hline Case & $\begin{array}{l}\text { Cellularity } \\
\text { (approx.) }\end{array}$ & $\begin{array}{l}\text { DNA (F) } \\
(\mathrm{ng} / \mu \mathrm{l})\end{array}$ & $\begin{array}{l}\text { DNA (S) } \\
\text { (ng/ul) }\end{array}$ & $\begin{array}{l}260 / 280 \\
\text { ratio }\end{array}$ & $\begin{array}{l}\text { Difference (S- } \\
\text { F) }\end{array}$ & $\begin{array}{l}\text { Total yield (F) } \\
\text { (ng) }\end{array}$ & $\begin{array}{l}\text { Total yield (S) } \\
\text { (ng) }\end{array}$ \\
\hline Cyto1 & 2000 & 1.21 & 31 & 2.54 & 29.79 & 48.4 & 1243 \\
\hline Cyto2 & 1000 & 2.71 & 55.03 & 1.69 & 52.32 & 108.4 & 2201 \\
\hline Cyto3 & 5000 & 1.43 & 158 & 2.14 & 156.57 & 57.2 & 6320 \\
\hline Cyto4 & 700 & 0.794 & 46.7 & 1.78 & 45.90 & 31.76 & 1868 \\
\hline Cyto5 & 1500 & 2.82 & 622 & 1.88 & 619.18 & 112.8 & 24880 \\
\hline Cyto6 & 1000 & 1.34 & 26.4 & 1.97 & 25.06 & 53.6 & 1056 \\
\hline Cyto7 & 1500 & 3.29 & 17.2 & 2.26 & 13.91 & 131.6 & 689.6 \\
\hline Cyto8 & 1500 & 3.12 & 18.4 & 3.23 & 15.28 & 124.8 & 736 \\
\hline Cyto9 & 5000 & 16 & 195 & 1.95 & 179 & 640 & 7800 \\
\hline Cyto10 & 1000 & 0.355 & 19.83 & 1.64 & 19.475 & 14.2 & 793.2 \\
\hline
\end{tabular}

\section{TABLE 3: DNA values from cytology smears}

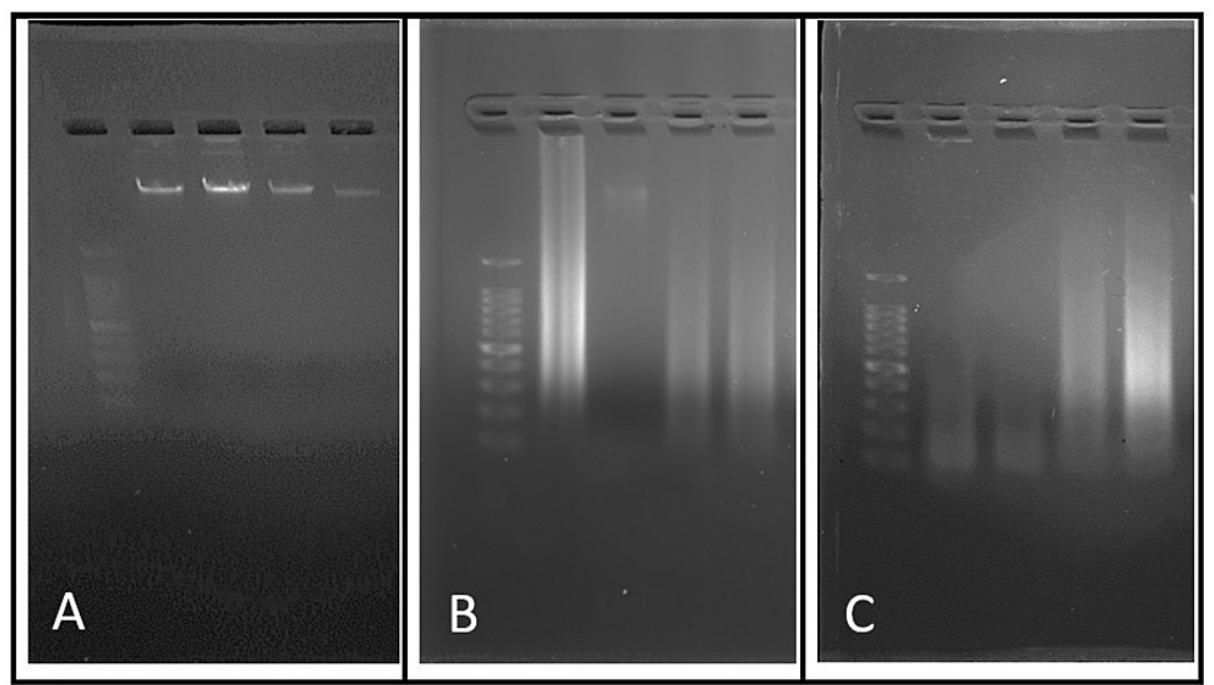

FIGURE 1: Gel electrophoresis done on 1.5\% agar with DNA extracted from A) Whole blood, B) Cytology smears C) FFPE blocks

Well 1 (A,B,C) - 100bp ladder

FFPE- formalin-fixed paraffin-embedded

Wilcoxin signed ranked tests were applied on the values obtained from the spectrophotometer and fluorometer. Statistically significant difference was noted between the values obtained from all the three sample types using the two different modalities of DNA estimation (Table 4). 


\section{Cureus}

\begin{tabular}{|c|c|c|c|c|c|c|c|c|c|c|}
\hline & \multicolumn{3}{|c|}{ Fluorometer (ng/pl) } & \multicolumn{3}{|c|}{ Spectrophotometer (ng/pl) } & \multicolumn{3}{|c|}{ Difference $(n g / \mu l)(S-F)$} & \multirow[t]{2}{*}{ P-Value } \\
\hline & Mean & Range & Median & Mean & Range & Median & Mean & Range & Median & \\
\hline Blood & 10.99 & $4.6-23.0$ & 8.85 & 29.76 & $20.7-46.9$ & 28.65 & 18.78 & $5.7-27.7$ & 18.6 & 0.006 \\
\hline FFPE & 1.9 & $0.0 .15-4.9$ & 1.28 & 69.9 & $15.1-229$ & 37.8 & 68.01 & $12.75-228.8$ & 37.27 & 0.002 \\
\hline FNA & 3.3 & $0.36-16$ & 2.07 & 119.9 & $17.2-622$ & 38.85 & 115.65 & $13.9-619.18$ & 37.85 & 0.002 \\
\hline
\end{tabular}

TABLE 4: DNA assay values from blood, core biopsies and FNAC samples. P-Value is obtained from Wilcoxin signed rank test between the Fluorometer and Spectrophotometer values.

S- Spectrophotometer, F- Fluorometer, FNAC- fine needle aspiration cytology, FFPE- formalin-fixed paraffin-embedded

\section{Discussion}

In molecular diagnostics, a major and critical step that influences the accuracy of test is availability of high quality genomic DNA [11]. Quality and quantity of DNA both have an impact on polymerase chain reaction (PCR) efficiency. Therefore, it is also essential to evaluate and compare the techniques for DNA assay. As evident from the results, both core biopsies and FNA samples have comparative DNA yields when measured using fluorometer. While estimating DNA quantity using spectrophotometer, the results were widely fluctuating with average DNA yield by spectrophotometer and fluorometer ratio (qS/qF) of 36.55 and 35.97 respectively for FFPE and FNAC samples. In the fresh blood samples, the qS/qF ratio was found to be 2.71 . These findings were in concordance with similar studies conducted by Kumar et al., Deben et al. and O'Neill et al. $[5,10,12]$.

In a fluorometer, nucleic acids are quantified using highly sensitive and accurate fluorescent dyes. Separate dyes are used for double-stranded (ds) DNA, single-stranded (ss) DNA or RNA estimation which increases its specificity. Binding of the dye to dsDNA emits fluorescence at a specific wavelength which is then estimated by the fluorometer and the DNA is quantified. This eliminates the possibility of contamination by RNA, free nucleotides and other proteins. Nakayama et al. demonstrated a good correlation between FFPE-DNA estimated using fluorometer and quantitative (q) PCR, while DNA was significantly overestimated by spectrophotometer [9]. They also postulated that while qPCR may be the most accurate method to estimate DNA quantity and purity, it is very expensive and impractical for routine use and fluorometers offer a cheaper and relatively accurate alternative.

Spectrophotometers use the principle of light absorbance at $260 \mathrm{~nm}$ by the nucleic acids. In general, it doesn't distinguish between dsDNA, RNA, proteins or free nucleotides in the sample leading to potentially overestimation of DNA content. When extracting DNA from processed samples like FFPE and FNA smears, it has to be borne in mind that the tissue is subjected to numerous physical and chemical agents which leads to fragmentation of the DNA and potentially increasing the chance of contamination by chemicals. Modification is introduced by chemicals results in protein cross-links between protein and DNA, deamination and adduct formation [13]. Consequence of these modifications result in deterioration of quality and number of amplifiable DNA templates which has a significant effect on PCR sensitivity and specificity [14]. In contrast, fresh blood has relatively preserved DNA along with fewer contaminants. This hypothesis was amply evidenced by our test findings which showed significant differences when using the two methods of DNA estimation.

On comparison of DNA yield from scraped smears and FFPE section it was seen that the average yield of DNA from a single scraped smear with adequate cellularity was greater than $3 \times 10$-micron sections from FFPE. FFPE sections showed the least correlation between fluorometric and UV spectrophotometric data. FNAC smears yield whole nuclei and do not undergo extensive processing and fixation unlike FFPE sections, and hence may be considered a preferred alternative to FFPE sections or cell blocks [15]. One major drawback in using FNAC smears is that the slides are destroyed while extracting DNA, and hence in cases having limited slides, photomicrographs need to be taken of the representative areas before extraction. In a study by Hartley et al. they demonstrated that DNA yield per nuclear area is better in FNAC smears and FFPE samples require more DNA quantity to achieve comparable mutation detection rates [16].

\section{Conclusions}

Spectrophotometry-based estimation of DNA is highly inaccurate. This inaccuracy increases when using DNA extracted from FFPE and FNAC specimens, but is also less accurate for DNA extracted from fresh blood. Fluorometry-based DNA estimation is more accurate and precise than spectrophotometry in FFPE, FNAC and whole blood samples. Fluorometry-based estimation should always be preferred over spectrophotometer results for quantification of DNA for downstream studies especially when working on core biopsies, FNAC 
smears or tissue specimens as demonstrated in the study. The present study also confirmed that average DNA yield from FNAC smears was superior or equivalent to DNA yield from FFPE sections and should be considered as a suitable alternative in molecular testing.

\section{Additional Information \\ Disclosures}

Human subjects: Consent was obtained or waived by all participants in this study. Institutional ethics committee, AIIMS, Rishikesh issued approval N/A. This study was conducted as a part of a quality assurance audit in our department to find whether DNA quantified by UV vis spectrophotometry could be a reasonable alternative to fluorometry for quantifying DNA as well as to see whether material obtained from FNA slide scrapings were equivalent to that obtained from core biopsies or blood. Since this was a quality assurance study, this is exempted from institutional ethics review as per Indian Council for Medical Research ethical guidelines. Animal subjects: All authors have confirmed that this study did not involve animal subjects or tissue. Conflicts of interest: In compliance with the ICMJE uniform disclosure form, all authors declare the following: Payment/services info: All authors have declared that no financial support was received from any organization for the submitted work. Financial relationships: All authors have declared that they have no financial relationships at present or within the previous three years with any organizations that might have an interest in the submitted work. Other relationships: All authors have declared that there are no other relationships or activities that could appear to have influenced the submitted work.

\section{Acknowledgements}

We thank Mr Chandan Kumar (Technical Assistant, AIIMS, Rishikesh) for his technical support during the experiments.

\section{References}

1. Goelz SE, Hamilton SR, Vogelstein B: Purification of DNA from formaldehyde fixed and paraffin embedded human tissue. Biochem Biophys Res Commun. 1985, 130:118-26. 10.1016/0006-291x(85)90390-0

2. Yokota M, Tatsumi N, Tsuda I, Yano I: DNA extraction and amplification from Giemsa-stained blood smears. J Clin Lab Anal. 1995, 9:387-91. 10.1002/jcla.1860090609

3. Betz BL, Roh MH, Weigelin HC, et al.: The application of molecular diagnostic studies interrogating EGFR and KRAS mutations to stained cytologic smears of lung carcinoma. Am J Clin Pathol. 2011, 136:564-71. 10.1309/AJCP84TUTQOSUONG

4. Lavarino C, Corletto V, Mezzelani A, et al.: Detection of TP53 mutation, loss of heterozygosity and DNA content in fine-needle aspirates of breast carcinoma. Br J Cancer. 1998, 77:125-30. 10.1038/bjc.1998.20

5. Kumar D, Panigrahi MK, Suryavanshi M, Mehta A, Saikia KK: Quantification of DNA extracted from formalin fixed paraffin-embeded tissue comparison of three techniques: effect on PCR efficiency. J Clin Diagn Res. 2016, 10:1-3. 10.7860/JCDR/2016/19383.8407

6. Didelot A, Kotsopoulos SK, Lupo A, et al.: Multiplex picoliter-droplet digital PCR for quantitative assessment of DNA integrity in clinical samples. Clin Chem. 2013, 59:815-23. 10.1373/clinchem.2012.193409

7. Huang LH, Lin PH, Tsai KW, Wang LJ, Huang YH, Kuo HC, Li SC: The effects of storage temperature and duration of blood samples on DNA and RNA qualities. PLoS One. 2017, 12:e0184692. 10.1371/journal.pone.0184692

8. Schmid FX: Biological macromolecules: UV-visible spectrophotometry. Encyclopedia of Life Sciences. John Wiley \& Sons Ltd, Chichester; 2001. 10.1038/npg.els.0003142

9. Nakayama Y, Yamaguchi H, Einaga N, Esumi M: Pitfalls of DNA quantification using DNA-binding fluorescent dyes and suggested solutions. PLoS One. 2016, 11:e0150528. 10.1371/journal.pone.0150528

10. O'Neill M, McPartlin J, Arthure K, Riedel S, McMillan ND: Comparison of the TLDA with the Nanodrop and the reference Qubit system. J Phys Conf Ser. 2011, 307:012047. 10.1088/1742-6596/307/1/012047

11. Sarnecka AK, Nawrat D, Piwowar M, Ligęza J, Swadźba J, Wójcik P: DNA extraction from FFPE tissue samples - a comparison of three procedures. Contemp Oncol (Pozn). 2019, 23:52-8. 10.5114/wo.2019.83875

12. Deben C, Zwaenepoel K, Boeckx C, et al.: Expression analysis on archival material revisited: isolation and quantification of RNA extracted from FFPE samples. Diagn Mol Pathol. 2013, 22:59-64. 10.1097/PDM.0b013e318269de3b

13. Dedhia P, Tarale S, Dhongde G, Khadapkar R, Das B: Evaluation of DNA extraction methods and real time PCR optimization on formalin-fixed paraffin-embedded tissues. Asian Pac J Cancer Prev. 2007, 8:55-9.

14. Rait VK, Zhang Q, Fabris D, Mason JT, O'Leary TJ: Conversions of formaldehyde-modified 2'deoxyadenosine 5'-monophosphate in conditions modeling formalin-fixed tissue dehydration. J Histochem Cytochem. 2006, 54:301-10. 10.1369/jhc.5A6725.2005

15. Chen H, Luthra R, Goswami RS, Singh RR, Roy-Chowdhuri S: Analysis of pre-analytic factors affecting the success of clinical next-generation sequencing of solid organ malignancies. Cancers (Basel). 2015, 7:1699715. 10.3390/cancers7030859

16. Hartley CP, Mahajan AM, Selvaggi SM, Rehrauer WM: FNA smears of pancreatic ductal adenocarcinoma are superior to formalin-fixed paraffin-embedded tissue as a source of DNA: comparison of targeted KRAS amplification and genotyping in matched preresection and postresection samples. Cancer Cytopathol. 2017, 125:838-47. 10.1002/cncy.21935 